\title{
Investigating the effect of social networking site use on mental health in an 18-34 year-old general population; a cross- sectional study using the 2016 Scania Public Health Survey
}

\author{
Emily Stella Scott@, Catarina Canivet(i) and Per-Olof Östergren* ${ }^{*}$
}

\begin{abstract}
Background: Social Networking Sites (SNS) are commonly used, especially by young adults. Their impact on mental health is unclear. Moreover, little is known about how social factors, e.g. Perceived Emotional Support (PES), may affect this association. Mental health issues are increasingly burdening the young generation and society as a whole. This study aims to investigate the association between frequency of SNS use and number of SNS contacts with the mental health of a young, Swedish population. Additionally, the potential effect modification of PES will be analysed in regard to these relationships.

Method: This cross-sectional study applied logistic regression analyses to data on 1341 participants (aged 18-34), retrieved from the Scania Public Health Survey (2016). Analyses were stratified by gender and the GHQ-12 scale assessed poor mental health. A 2-way interaction model was used to test for effect modification by PES regarding the association between SNS use and mental health.

Results: Increased risk for poor mental health was found in women only. Using SNS almost hourly vs. less often resulted in an odds ratio $(\mathrm{OR})$ of $1.66(95 \%$ confidence interval $(\mathrm{Cl})=1.16-2.38)$. The corresponding figures for having $\geq 600$ contacts vs. $\leq 599$ were $(1.89 ; 1.21-2.97)$. Having low PES and using SNS almost hourly was associated with an OR of $3.12(C l=1.69-5.76$; synergy index $(S I)=1.25)$. Low PES and $\geq 600$ contacts resulted in an OR of 6.07 $(\mathrm{Cl}=1.73-21.33)$, whereby interaction was detected $(\mathrm{SI}=2.88)$.

Conclusion: Women, but not men, with frequent SNS use and a high number of SNS contacts were more likely to have poor mental health, which was exacerbated in women with low PES. Facilitating PES could be an approach for improving mental health among young adults. Future studies on the use of SNS should focus more on gender analyses.
\end{abstract}

Keywords: Online social networking, Social media, Mental health, Gender, Young adult, Social support, Perceived emotional support

\footnotetext{
* Correspondence: per-olof.ostergren@med.lu.se

Social Medicine and Global Health, Department of Clinical Sciences Malmö,

Lund University, Lund, Sweden
}

C C The Author(s). 2020 Open Access This article is licensed under a Creative Commons Attribution 4.0 International License, which permits use, sharing, adaptation, distribution and reproduction in any medium or format, as long as you give appropriate credit to the original author(s) and the source, provide a link to the Creative Commons licence, and indicate if changes were made. The images or other third party material in this article are included in the article's Creative Commons licence, unless indicated otherwise in a credit line to the material. If material is not included in the article's Creative Commons licence and your intended use is not permitted by statutory regulation or exceeds the permitted use, you will need to obtain permission directly from the copyright holder. To view a copy of this licence, visit http://creativecommons.org/licenses/by/4.0/ The Creative Commons Public Domain Dedication waiver (http://creativecommons.org/publicdomain/zero/1.0/) applies to the data made available in this article, unless otherwise stated in a credit line to the data. 


\section{Background}

The invention and widespread use of Social Networking Sites (SNS) has arisen alongside the New Media Age. Websites such as Facebook, Instagram or Twitter were designed primarily for communication purposes, where one can instantly message contacts, share photos, videos, or statements [1]; but also for entertainment, socialising or sharing news. As the use of SNSs is still a relatively novel phenomenon, the long- and short-term effect on health, especially mental health, is somewhat unknown and largely controversial [2,3]. In Sweden, the number of SNS users has risen steadily. In 2017, $81 \%$ of the population aged above 12 were using them, $56 \%$ on a daily basis; compared to 53 and $28 \%$, respectively, in 2010. Individuals aged between 12 and 35 most commonly use SNS on a daily basis, women more than men. The most commonly used site in Sweden is Facebook, whereby in 2017, 76\% of Internet users aged 16-25 and 74\% aged 26-35 used Facebook on a daily basis [4].

Mental health problems are on the rise worldwide [5], largely due to an increase in depression [5, 6]. Depressive disorders reside in the top three leading causes of Years Living with Disabilities (YLD), globally [6], with recent estimates predicting around 270 million affected individuals [5]. Depression correlates with an increased mortality, especially suicide [7], which is the second most common cause of death among 15-29-year olds [5]. In Sweden, the level of poor mental health in children and young adults has also risen in recent years, with no apparent aetiology [8]. The parallel rise in SNS use and poor mental health prevalence among young adults may suggest the former is affecting the latter [9].

\section{Mental health and frequency of SNS use}

It has been postulated that the mechanism linking SNS use and mental health issues may be increased time spent on SNS, thereby interfering with routine obligations and functioning [3]. One longitudinal study, using the experience sampling method, showed that increased SNS use predicted declines in affective well-being and life satisfaction [10]. Users may expect to 'feel better than before' after using Facebook for about $20 \mathrm{~min}$, according to a three-part study on Facebook's emotional consequences [11]. However, in an experimental part of this same study, increased time on Facebook prior to an assessment of emotional status correlated with negative mood [11]. Essentially, these results may suggest that if users' subjective well-being is consistently undermined over a sustained period, this could lead to depression [2].

However, some articles posit that there is no significant effect of frequency of SNS use on depression [12, 13]. Others suggest that certain types of activity and their specific SNS use predict depression. For example, passive SNS use (in the case of Facebook), would include browsing the newsfeed and reading contacts' posts and profiles. During active Facebook use, one is actively posting content, engaging with other people's content or communicating [2]. This could be an issue, because in an experimental and experience sampling study, passive Facebook use was shown to decrease affective well-being, whereas active Facebook use did not [14]. Several studies concern themselves with specific negative feelings associated with SNS use, such as envy [14, 15], loneliness [16] or worry [10]. For instance, the relationship between passive Facebook use and affective well-being was mediated by envy, so that passive Facebook use increased feelings of envy which in turn decreased well-being [14]. Similarly, Tandoc et al. (2015) [15] found that depression occurred when envy was triggered during passive Facebook use. If envy did not occur, use of Facebook correlated positively with lower levels of depression [15].

The majority of studies have investigated the use of Facebook [2], though the use of Instagram also seems relevant. In Sweden, Instagram is used by $52 \%$ of the population, mostly by younger individuals [4]. Frequency of Instagram use was positively correlated with depressive symptoms, anxiety and self-esteem issues in a cohort study of 129 women between 18 and 35 years of age. These associations were partially mediated by social comparison [17]. Similarly, in another study of a mixed gender population, more frequent use of Instagram was significantly positively associated with depression [18].

\section{Mental health and the number of SNS contacts}

The number of SNS contacts is a frequently studied factor that may influence the relationship between SNS use and mental well-being [2,3]. Considering the results of the studies from section Mental health and frequency of SNS use, these may suggest that more SNS contacts exposes the individual to more content that could be detrimental to their mental well-being, for example due to a tendency to compare themselves or ruminate. In the Instagram study, the number of accounts participants were following as well as the participants' number of followers correlated positively with depressive symptoms [17]. A further Instagram inquiry also found a positive association between Instagram use and symptoms of depression when following disproportionately more strangers than real life acquaintances. When following more acquaintances than strangers, increased Instagram use correlated with decreased depression [18]. This study is interesting in that it suggests there is a point at which following too many strangers can be detrimental to one's well-being. Moreover, having a high number of Facebook friends predicted worsened life satisfaction for those who used Facebook for making new connections as opposed to strengthening current friendships [19]. In contrast, a study with a Finnish population, of whom 
most were students, concluded that the number of Facebook friends had no association with happiness nor life satisfaction, as this was confounded by personality traits [20]. It seems reasonable to hypothesise that having increasingly more SNS friends increases the likelihood of a larger proportion of these being distant acquaintances, superficial types of relationships or even total strangers, as was revealed in a study of college students' Facebook friendship networks [21]. This might increase the exposure of other people's SNS profiles and posts with whom and which one is less familiar with, in turn increasing the chances of using SNS in a less active and more passive way. Alternatively, a higher number of online contacts may, via the same logic, potentially increase negative social comparison, fuelling feelings of envy and thereby contributing to depressive mood $[18,22]$.

\section{Perceived emotional support}

Perceived emotional support (PES) is defined as subjectively perceived support, which provides empathy or advice during times of trouble from important others, such as family, friends and partners, which differs from received support (the support you actually receive) [23]. Having low PES has been associated with increased depression and anxiety [24], poor general health, quality of life and other mental health outcomes [25].

Previously, interest in PES derived online from the use of SNS in association with mental well-being has been far greater, given SNS are social portals and so a potential source of PES [2]. However, it seems no study so far has investigated the role of "offline PES" in the relationship between SNS use and mental health. Understanding people's environmental social factors such as their level of PES, could yield a better understanding of the associations between SNS use and mental health. In addition, as the above account of studies has shown, it is unlikely to be social media use alone that impacts mental health, but rather a combination with other factors, such as personality and social support structures.

In summary, research into the impact of frequency of SNS use and network size on mental health has provided mixed findings [2]. The immense interest into this topic has fuelled the production of a large research literature. Yet, despite this, results are conflicting and largely inconclusive $[2,3]$. SNS are also constantly evolving; new networks join, while others lose in popularity [26], all while people's networks tend to expand [21].

The aim of this study was to examine the association of SNS use, in itself, and in relation to "offline PES", with mental health of young adults aged 18-34 in Sweden. More specifically, the questions are:

a) Does an association exist between frequency of SNS use or number of SNS contacts with mental health of young adults in Sweden? b) Are young adults living in Sweden who have a high level of PES protected from the potentially detrimental effects of frequent SNS use or having a large number of SNS contacts?

\section{Methods \\ Design, participants and setting}

The 2016 Scania Public Health Survey comprised individuals between 18 and 96 years of age. However, as most previous studies concerned younger populations, we decided to restrict this study to "young adults" (i.e. individuals between 18 and 34 years of age). The main reason for this was that the prevalence of high SNS use has been shown to be considerably lower among older individuals [4], which would invite a problem of statistical power. Thus, our sample comprised 1341 individuals (477 males and 864 females) (Table 1). A postal questionnaire has been sent out regularly in about 5year intervals, collecting data on health, employment, environment, and more, from randomly chosen individuals $18-80$ years of age residing in the county of Scania, southern Sweden [27]. In 1999, a cohort of the 13,589 individuals who responded to the survey was created, with young individuals being added to the cohort in 2010 and 2016. In the most recent survey in 2016, items tapping Internet behaviour were added. The individuals used in this study were between 5 and 21 years old when Facebook was made available to anyone with an e-mail address (accessibility beyond solely universities), provided they were aged 13 or above [28].

\section{Measures and variables}

Mental health was assessed using the 12-item General Health Questionnaire (GHQ-12). The GHQ-12 aims to detect psychiatric morbidity [29] and is intended for screening non-specific psychiatric illnesses of a nonsevere nature [30]. Though it is aimed at detecting minor mental distress and disorders in general, the test tends to be mostly indicative of depressive symptoms [31]. Each item has four responses, generally reading "better than usual", "the same as usual", "worse than usual" and "much worse than usual". At least $8 / 12$ questions had to be answered to be counted as a valid GHQ assessment. The Standard/GHQ scoring method (0-0$1-1$ ) was utilised (range $0-12$ ), as recommended by the creators of the instrument, with being a "GHQ-case" defined as a score of 2 or higher [32, 33]. The GHQ-12 scale has been found to be excellent for distinguishing depressive participants from healthy controls of a Swedish adult general population when using the GHQ scoring method, with sensitivity and specificity scores of 85.5 and 83.2, respectively [34].

Frequency of SNS use was measured using a singleitem categorical scale to assess the extent of activity on 
Table 1 Distribution of sociodemographic characteristics, social networking site (SNS) use, social characteristics and poor mental health

\begin{tabular}{|c|c|c|c|c|c|}
\hline \multirow[t]{2}{*}{ Variables (missing values) } & \multirow[t]{2}{*}{ Category } & \multicolumn{2}{|c|}{ Male } & \multicolumn{2}{|c|}{ Female } \\
\hline & & ns & $\%$ of valid total & ns & $\%$ of valid total \\
\hline \multirow[t]{2}{*}{ Age group } & $18-26$ & 263 & 55.1 & 495 & 57.3 \\
\hline & $27-34$ & 214 & 44.9 & 369 & 42.7 \\
\hline \multirow[t]{2}{*}{ Poor mental health } & No & 300 & 62.9 & 435 & 50.3 \\
\hline & Yes & 177 & 37.1 & 429 & 49.7 \\
\hline \multirow[t]{6}{*}{ Frequency of SNS use (4) } & Not at all & 49 & 10.3 & 35 & 4.1 \\
\hline & Max. a couple times/ month & 23 & 4.8 & 20 & 2.3 \\
\hline & A few times per week & 33 & 6.9 & 34 & 3.9 \\
\hline & At least once every day & 78 & 16.4 & 147 & 17.1 \\
\hline & Several times each day & 222 & 46.7 & 452 & 52.4 \\
\hline & Almost every hour & 70 & 14.7 & 174 & 20.2 \\
\hline \multirow[t]{3}{*}{ Number of SNS contacts (39) } & $0-299$ & 256 & 56.3 & 472 & 55.7 \\
\hline & $300-599$ & 142 & 31.2 & 273 & 32.2 \\
\hline & 600-999 & 57 & 12.5 & 102 & 12.0 \\
\hline \multirow[t]{3}{*}{ Main occupation (18) } & Working & 282 & 60.3 & 466 & 54.5 \\
\hline & Student & 140 & 29.9 & 262 & 30.6 \\
\hline & Other & 46 & 9.8 & 127 & 14.9 \\
\hline \multirow[t]{2}{*}{ Education (17) } & 13 yrs. or more & 262 & 55.6 & 558 & 65.4 \\
\hline & 12 yrs. or less & 209 & 44.4 & 295 & 34.6 \\
\hline \multirow[t]{3}{*}{ Relationship status (22) } & Single & 190 & 40.6 & 286 & 33.6 \\
\hline & Married/ cohabiting with partner & 211 & 45.1 & 444 & 52.2 \\
\hline & Other type of partnership & 67 & 14.3 & 121 & 14.2 \\
\hline \multirow[t]{2}{*}{ Born in Sweden (7) } & Yes & 415 & 87.4 & 768 & 89.4 \\
\hline & No & 60 & 12.6 & 91 & 10.6 \\
\hline \multirow[t]{4}{*}{ Perceived emotional support (5) } & Yes, for sure & 327 & 68.7 & 637 & 74.1 \\
\hline & Yes, probably & 102 & 21.4 & 164 & 19.1 \\
\hline & Not quite sure & 33 & 6.9 & 41 & 4.8 \\
\hline & No & 14 & 2.9 & 18 & 2.1 \\
\hline
\end{tabular}

Poor mental health is defined by the GHQ-12. Results represent the total population of participants aged 18-34 (N=1341 (477 male and 864 female)) and are presented by gender. Data are gained from the Scania Public Health Cohort 2016

SNS, such as Facebook, Twitter, Instagram and so on. Participants indicated their frequency of use during the last 12 months from the categories, "not at all", "maximum a couple times per month", "a few times per week", "at least once per day", "several times each day" and "almost every hour". This variable was, based on its distribution, dichotomised to "almost every hour" and "less than almost every hour".

Number of SNS contacts was measured using a singleitem continuous scale, in which participants entered "Approximately how many friends or contacts they have in social media" in 3 available boxes, therefore answers range from 0 to 999 contacts. This item was also dichotomised based on its distribution to $\leq 599$ or $\geq 600$ contacts.

Perceived emotional support was assessed using a single item phrased "Do you feel that you have anyone or some people that can give you real personal support to manage life's stresses and problems?". Answers included "Yes, for sure", "Yes, probably", "Not quite sure" and "No", which were dichotomised to High and Low, whereby Low included the latter three answers. The question encompasses social support received from any person, be it family, friends or significant others [24].

Several background variables were considered to potentially influence the true result. Age was kept as a continuous variable in analyses but was dichotomized by the median to groups aged $18-26$ and $27-34$ in Tables 1 and S1 (Supplementary file 1). Gender was defined as "male" or "female". Relationship status included "Married to or cohabiting with partner", "Single" and "Other type of partnership", whereby the latter may be a longdistance partnership, for example. This variable was 
dichotomised to "Married to or cohabiting with partner" and "Single or Other type of partnership". Current main occupation included categories "Working", "Student" and "Other", whereby "Student and Other" was combined to one category. Working persons included all that worked either full time or part-time (due to being partially on sick leave, unemployed or retired). Students included all persons studying, whether they were also employed or not. The "other" category included "Labour market action", e.g. "trainee", "completely unemployed", "home-maker without economic reimbursement", "retired full-time", "long-term sick leave" and "parental leave".

\section{Statistical methods and data analysis}

The relationships between background factors and mental health are presented as numbers, frequencies and odds ratios. Further, logistic regression analyses were performed, using the IBM SPSS programme version 25 . An alpha level of $\leq 5 \%$ was required for statistical significance. For the two multivariate models, several background variables were logically considered to be potential confounders, such as gender, age, educational level, current main occupation, relationship status, born in Sweden and PES [35]. If statistically significant, the variables were added in a stepwise manner to the regression models (Tables S2 and S3, see Supplementary files 2 and 3, respectively) [36]. Age as a continuous variable was not a significant predictor to the outcome, although when dichotomised and categorised in the female regression analysis, some significantly increased odds was found for the 18-26 age group (Table S1, Supplementary file 1). However, the primary reason for keeping age in the model was for comparability purposes. The gender variable was further analysed by splitting the file, whereby it became clear that the association between exposure and outcome was only evident in females. All subsequent analyses were therefore conducted separately for gender. The variables main occupation, relationship status and PES were all statistically significantly associated with mental health, and they were thus included in the logistic regression models.

Possible effect modification by PES on the association between the two main exposures and mental health was analysed using Rothmans method for creating interaction terms [37], for the females only. Synergy index was calculated using the following equation [37]:

$$
(\mathrm{OR}-1)_{\mathrm{EXP}++} /\left((\mathrm{OR}-1)_{\mathrm{EXP}+-}+(\mathrm{OR}-1)_{\mathrm{EXP}-+}\right) .
$$

\section{Results}

\section{Descriptive statistics}

Table 1 shows the sociodemographic data for the population investigated. More females $(n=864 \quad(64.4 \%))$ partook in the survey than males $(n=477(35.6 \%))$. Half the female population considered themselves to have poor mental health (49.7\%) compared to males with a comparatively lower prevalence (37.1\%). Around half the population use SNS several times every day (46.7 and $52.4 \%$ for men and women, respectively). The proportion of females that reported that they did not use SNS at all, was considerably lower (only 4.1\%) compared to males (10.3\%). The number of SNS contacts distribution is very much equal across genders, but most participants have under 300 friends. Having low PES is generally less common, though slightly more prevalent among men $(31.2 \%$ for men vs. $26.0 \%$ for women).

\section{Research question a) SNS exposures and mental health}

Cross-tabulations and regression analyses in Table S1 (see Supplementary file 1) showed more detailed discrepancies between genders, in that poor mental health prevalence in the "Almost every hour" category increased for women (62.6\%) and remained relatively stable for men (38.6\%) compared to the reference group. The same prevalence pattern was seen in the number of SNS contacts between genders. Women who reported using SNS almost every hour had an odds ratio (OR) of 1.94 $(\mathrm{CI}=1.38-2.73)$ concerning GHQ case status compared to those that reported using SNS less than almost every hour. Similarly, women with $\geq 600$ SNS contacts had an OR of $1.79(\mathrm{CI}=1.17-2.74)$ regarding poor mental health compared to women who reported having fewer than 600 contacts. The mean number of SNS contacts for women was 288 (standard deviation $(\mathrm{SD})=223$ ) and for men 284 $(\mathrm{SD}=246)$. PES was highly associated with being a GHQ-case, whereof only a slight difference between genders was noticeable.

Tables S2 (see Supplementary file 2) and S3 (see Supplementary file 3) show the multivariate logistic regression models for the two relationships of interest, namely frequency of SNS use and number of contacts with poor mental health, respectively. For females, the independent effects of association between frequency of SNS use and poor mental health remained strong (OR $1.66(\mathrm{CI}=$ 1.16-2.38)) in the fully adjusted model (Model 3). A slight decreasing trend occurred after stepwise adjustment (Models 1, 2 and 3). However, the only other significantly associated exposure variable was PES (OR 1.96 $(\mathrm{CI}=1.42-2.71))$, whereas age, main occupation and relationship status were not. The same pattern was seen in Table S3 (see Supplementary file 3), which demonstrates that the fully adjusted Model 3 association between number of SNS contacts and poor mental health remained statistically significant (OR 1.89 (CI $=1.21$ $2.97)$ ). Neither of the associations of interest (Tables S2 and S3, Supplementary files 2 and 3) were much affected by the potentially confounding variables. For males there 
was no association demonstrated in Model 3 concerning any of the two main exposure variables, after full adjustment of the chosen covariates (Table S2: OR 0.94 $(\mathrm{CI}=$ 0.54-1.66), and Table S3: OR $0.96(\mathrm{CI}=0.52-1.76))$.

\section{Research question b) PES and mental health}

This section builds on the first research question by aiming to detect how PES moderates the effect of frequency of SNS use and the number of SNS contacts regarding mental health. Provided the non-existing bivariate association in males, the subsequent analysis was not included for them.

Table 2 shows that among those who reported being active on SNS almost every hour, the effect on mental health was highest for those who simultaneously reported low PES, OR $3.12(\mathrm{CI}=1.69-5.76)$. However, the evidence for significant effect modification between the mentioned exposure variables was weak, $\mathrm{SI}=1.25$.

Similarly, Table 3 shows that among those who reported having $\geq 600$ contacts on SNS, the effect on mental health was highest among those who at the same time reported having low PES, OR $6.07(\mathrm{CI}=1.73-21.33)$. In this case, there was an indication that the level of PES modified the effect of having many SNS contacts on mental health, so that low PES reinforced the negative effect of having a large number of contacts, $\mathrm{SI}=2.88$.

\section{Discussion}

The findings of this study indicate an association between high frequency of SNS use and a large network size on the one side and poor mental health on the other side, among Swedish young female adults. Furthermore, it shows that this association is modified by the level of PES. Women who used SNS on an almost hourly basis had increased odds of experiencing poor mental health than when using the platforms less frequently, as well as when having more than 600 contacts on SNS compared to fewer. Women with high PES seemed largely protected from the detrimental effects of having more than 600 SNS contacts.

Despite the widespread knowledge that women, especially young women [38], are more frequently burdened by depression than men [39], it seems somewhat surprising that very few studies have specifically looked into the difference of impact between genders in SNS use and mental health $[2,3]$.

\section{Early age gender difference}

In a recent, longitudinal UK study, girls and boys aged 10-15 showed decreasing happiness and increasing active SNS usage [40]. Additionally, socio-emotional difficulties (emotional, peer-relationship and conduct problems) rose for girls but declined for boys. The increased use of SNS at age 10 was associated with decreased happiness and increased socio-emotional difficulties in later years thereafter (up to age 15), in girls only. This study showed how at a very young age, use of SNS can affect girls' well-being in later adolescent years [40]. It is thought that since the adolescent years shape one's future physical and mental health to a large extent [41], many adolescents experiencing mental health issues during this crucial developmental period will go on to experience such issues in later years, especially in their 20's [42]. Hence, a decline in well-being due to SNS use occurring from an early age onwards, could escalate and result in mental health issues in later young adult years. However, it may be, that this trend reverses beyond the young adult years, as women aged $27-34$ in this study were slightly less likely to indicate poor mental health (Table S1).

Another study of an adolescent population with a mean age of 15 years found that passive Facebook use increased depressed mood in girls only, whereas active, public (posting content on their profiles) Facebook use was associated with depressed mood in boys. However, active public and private use in girls yielded positive outcomes when they perceived online social support [43]. Together, these studies suggest that SNS use affects children already at a young age, that these effects vary by gender, and by the way in which the sites are used.

\section{Problematic Facebook use $\&$ a gender perspective}

A meta-analysis on Problematic Facebook Use (PFU), or Facebook addiction, suggested that females were more prone to demonstrate PFU behaviour than males [44]. One definition of PFU is such Facebook usage that disrupts everyday life at school, work or with relationships, by causing distress in cognitive functioning and/or well-

Table 2 Synergistic interaction effects between SNS use frequency and PES on poor mental health among females

\begin{tabular}{llll}
\hline Category & Total N (\% of valid total) & Cases N (\% within category) & OR (95\% CI) \\
\hline Less than almost every hour \& high PES & $506(60.4)$ & $216(42.7)$ & 1 (ref) \\
Almost every hour \& high PES & $115(13.7)$ & $67(58.3)$ & $1.70(1.12-2.59)^{*}$ \\
Less than almost every hour \& low PES & $162(19.3)$ & $98(60.5)$ & $2.00(1.39-2.87)^{*}$ \\
Almost every hour \& low PES & $55(6.6)$ & $39(70.9)$ & $3.12(1.69-5.76)^{*}$ \\
Total & $838(100)^{\mathrm{a}}$ & $420(50.1)$ & $\mathrm{SI}=1.25$ \\
\hline
\end{tabular}

Results are presented as total numbers, numbers and percentages of cases of poor mental health within each category, odds ratios (OR) with $95 \%$ confidence intervals $(95 \% \mathrm{Cl})$, and the synergy index $(\mathrm{SI})$. Interactions were controlled for age, main occupation and relationship status. Data are gained from the Scania Public Health Cohort 2016. Total number of female Swedish young adults $=838^{\mathrm{a}}$. a: Missing values $=26(3.0 \%)$. ${ }^{*}$ Significant result $=p<0.05$ 
Table 3 Synergistic interaction effects between number of SNS contacts and PES on poor mental health among females

\begin{tabular}{llll}
\hline Category & Total N (\% of valid total) & Cases N (\% within category) & OR (95\% CI) \\
\hline 0-599 contacts \& high emotional support & $530(64.2)$ & $233(44.0)$ & $1($ ref) \\
600-999 contacts \& high emotional support & $80(9.7)$ & $48(60.0)$ & $1.75(1.08-2.85)^{*}$ \\
0-599 contacts \& low emotional support & $198(24.0)$ & $122(61.6)$ & $2.01(1.43-2.81)^{*}$ \\
600-999 contacts \& low emotional support & $18(2.2)$ & $15(83.3)$ & $6.07(1.73-21.33)^{*}$ \\
Total & $826(100)^{\text {b }}$ & $418(50.6)$ & $\mathrm{SI}=2.88$ \\
\hline
\end{tabular}

Results are presented as total numbers, numbers and percentages of cases of poor mental health within each category, odds ratios (OR) with $95 \%$ confidence intervals $(95 \% \mathrm{Cl})$, and the synergy index $(\mathrm{SI})$. Interactions were controlled for age, main occupation and relationship status. Data are gained from the Scania Public Health Cohort 2016. Total number of female Swedish young adults $=826^{\mathrm{b}}$. b: Missing values $=38(4.4 \%)$. ${ }^{*}$ Significant result $=p<0.05$

being [44]. In a meta-analysis of 23 studies with adolescent and young adult populations, PFU was positively associated with depression, anxiety and psychological distress in general [45]. Marino et al. (2018) found that time spent on Facebook correlated with PFU [44]. Females in the present study who reported using SNS almost hourly could in fact be described as exercising PFU behaviour. Of course, frequency of SNS use does not completely equate to time spent on Facebook, but the two variables go hand in hand. PFU individuals tended to have larger friendship networks compared to non-PFU individuals, and females with PFU also tended to send more friend requests and private messages [46]. It has been repeatedly shown that women use SNS for communicating, maintaining friendships and accessing social information, whereas men tend to use the platforms more for gaining information and playing games [47-49]. A deeper understanding as to why women use SNS more and are potentially also detrimentally affected by them could be provided by a gender perspective [50]. Essentially, gender roles are transposing onto the use of SNS, so that women are more attracted to use SNS for social connectivity than men [43, 47]. For example, the behaviour to compare oneself on SNS is more common among women than men [51]. Indeed, increased Facebook use has been linked to increased social comparison, fuelling envy, and resulting in depression, which is partially grounded in causal evidence [22]. A difference between genders has also been detected, in that adolescent females who tended to compare themselves on SNS had worse depression outcomes [52]. Interestingly, when the number of SNS contacts was analysed in this study as a continuous variable, there was a statistically significant association between each additional contact and being a case for poor mental health in the female population, with an incremental chance of $0.1 \%$, OR $1.001(\mathrm{CI}=1.00-1.001)$. Though a small value, it is nonetheless meaningful, considering the number of contacts are as many as several hundred for many SNS users. Also, females have been shown to emotionally respond worse to negative images or messages, which may provide further explanation for the poorer health outcomes [50].

Our finding regarding the gender difference in the association between number of SNS contacts and mental health appears to be the first such finding reported in the scientific literature.

\section{No gender differences}

Some studies do not show differences in gender, such as Kross et al. (2013) [10], where declines in subjective well-being, associated with frequent Facebook use, were not moderated by gender. Gender was also accounted for by Verduyn et al. (2015) [14], however it did not moderate the relationships [14]. Although SNS use was associated with body image and eating disorders, this meta-analytic association did not differ between men and women in studies that examined gender [53].

It may be that a true association between SNS use and mental health has been clouded by combining gender in analyses, contributing to the mixed findings in the literature. Although most studies controlled for gender, a deeper analysis as in the above studies (sections Early age gender difference and No gender differences) has been the exception.

\section{PES \& SNS use}

Women are, in the absence of emotional support, significantly more prone to depression than men [54]. This was corroborated by the findings in this study. Similarly, in another Swedish study of late adolescents, women benefitted more than men in their psychological wellbeing from high-quality, trusting friendships [55]. The findings in our study showed that high PES protected very frequent SNS users from a negative impact on their mental health. However, the current findings may be an artefact in that persons with low PES inherently use SNS more than individuals with high PES, as a meta-analytic study showed low PES led to loneliness, which subsequently led to increased Facebook use [16]. A further study, which aimed to investigate PFU, performed a 3way interaction analysis between PFU, neuroticism and well-being, which differed according to gender. Women high in PFU and neuroticism were at 17 times higher odds of having low mood compared to men low in 
neuroticism and PFU [56]. It has been shown that neuroticism and PES are related, in that females high in neuroticism also perceive lower emotional support [57], suggesting a similar finding to ours regarding the interaction between frequency of SNS use and low PES.

Most PES inquiries are concerned with online-derived support rather than offline ditto [2]. For example, one such inquiry found that larger Facebook networks were associated with increased perceived online social support as well as life satisfaction [21]. Further analysis in the above-mentioned study found a negative curvilinear relationship between the number of SNS contacts and perceived social support [58]. This meant that from a certain number and up to a certain number of Facebook friends, these provided perceived social support, but beyond these points, no or too little support was derived; the authors suggest this may be due to the time and effort devoted to friends becoming too much or too little, thereby contributing detrimentally [58]. Further comparable studies are sparse, so that the finding of effect modification by PES on the association between SNS use and mental health appears to be a novel finding.

\section{Methodological considerations \& limitations}

The main limitation of this study is the cross-sectional design, which does not exclude causal effects in both directions between the main variables, and it is not unlikely that the causal mechanism may be bidirectional. Since non-response was not negligible, selection bias could be an issue and theoretically leading to either overestimation or underestimation of the found associations. However, it seems unlikely to be the major explanation of the findings. A strength of this study is the comparatively large sample size, which reduces the risk of random error. The main exposure variables were developed by one of the authors due to lack of wellvalidated alternatives, and are rather straight-forward questions on frequency of SNS use and number of contacts which are unlikely to be misunderstood by the respondents or to be an issue of other types of response bias. Since self-reported SNS use may be under-reported when compared to actual use, there is a risk of differential misclassification (i.e. if some high users with poor mental health were erroneously classified as non-highusers), and thus, our findings may represent an underestimation of the true effect [59]. The outcome variable was measured by a very well-validated instrument, which also reduces the likelihood of misclassification. The associations were controlled for the most obvious potential confounders: age, occupation, relationship status, as well as PES, which does not exclude bias from confounding, but ought to render it a less likely explanation of the found associations. Finally, the SNS measures used in this study were not specific to certain SNS. As these sites vary in their purpose of usage, interface and content, it would be beneficial to include separate SNS survey questions. Facebook is the most commonly studied SNS [2], hence also the literature presented here is biased towards Facebook. Having said that, most Swedes use Facebook [4], therefore it is probable that these results are most applicable to Facebook.

\section{Conclusions}

Important findings emerged, in that statistically significant associations between frequency of SNS use and number of SNS contacts on one side, and mental health on the other side were found - albeit only among female participants. Furthermore, that this association was modified by the level of PES.

From this study's findings, it is suggested that future research conducts deeper gender analyses, whether through stratifying by gender, conducting separate analyses or limiting the study population. These findings also raise further questions, hence why it is necessary to deeply investigate how SNS are used by women compared to men, allowing for comparability and providing information on protective behaviours. Equally important is to investigate the possibility of a causal association by employing more longitudinal studies.

In light of this study, SNS use in women with mental health issues needs to be targeted. For instance, psychological strategies to enhance young women's PES could be utilised in therapy, at institutions (universities, schools) and within communities. Spreading understanding of potential detrimental effects of frequent SNS use or having relatively large SNS networks, and how to establish healthy SNS usage patterns, as well as form a SNS network that works to one's benefit, may be target areas with which to improve mental health outcomes.

\section{Supplementary Information}

Supplementary information accompanies this paper at https://doi.org/10. 1186/s12889-020-09732-z.

Supplementary file 1: Table S1. Sociodemographic characteristics, SNS use, and social characteristics, in relation to poor mental health.

Supplementary file 2: Table S2. Logistic regression showing the associations between frequency of SNS use and poor mental health. Supplementary file 3: Table S3. Logistic regression showing the associations between number of SNS contacts and poor mental health.

Abbreviations

SNS: Social networking site; PES: Perceived emotional support; GHQ: General health questionnaire

\section{Acknowledgements \\ None}

Authors' contributions

CC and POÖ developed the survey questions for the section of interest. ES conducted the literature research, data analysis, and writing of the 
manuscript. CC and POÖ subsequently reviewed all analyses and substantially contributed to the writing. All authors read and approved the final manuscript.

\section{Authors' information}

This manuscript was written by ES as a development of her master's thesis in Public Health at Lund University, through which POÖ guided her as supervisor.

\section{Funding}

This work was supported by grants from the Swedish Research Council for Health, Working Life and Welfare (FORTE; diary no. 2015-00885) and by the Medical Faculty at Lund University. The funding parties were not involved in the design, collection of data, analyses, or interpretation of data, authoring of the manuscript, or in any other aspect of the study. Open Access funding provided by Lund University.

\section{Availability of data and materials}

The datasets generated and/or analysed during the current study are available by request to the corresponding author.

\section{Ethics approval and consent to participate}

All the described procedures were approved by the Research Ethics Committee of Lund University (2016/622) and were in accordance with the 1964 Helsinki declaration and its later amendments or comparable ethical standards.

The respondents filled in a questionnaire sent to their home address by regular mail, which they also sent back by regular mail. In the beginning of the questionnaire, information regarding the study was given concerning the purpose, data security (guaranteed anonymity) and that participation was voluntary. It was also informed that sending back a completed questionnaire was considered to be consent to participate.

\section{Consent for publication}

Not applicable.

\section{Competing interests}

The authors declare that they have no conflict of interest.

\section{Received: 1 April 2020 Accepted: 19 October 2020}

Published online: 23 November 2020

\section{References}

1. Cambridge Dictionary. Social networking site. 2019. https://dictionary.cambridge.org/ dictionary/english/social-networking-site. Accessed 18 Feb 2020.

2. Seabrook EM, Kern ML, Rickard NS. Social networking sites, depression, and anxiety: a systematic review. JMIR Ment Health. 2016;3(4):e50.

3. Frost RL, Rickwood DJ. A systematic review of the mental health outcomes associated with facebook use. Comput Hum Behav. 2017;76:576-600.

4. Statista Inc. Social media usage in Sweden. 2019. https://www-statista-com. ludwig.lub.lu.se/study/38898/social-media-usage-in-sweden-statista-dossier/. Accessed 15 Feb 2020.

5. World Health Organisation. Depression. 2017. http://www.who.int/ mediacentre/factsheets/fs369/en/. Accessed 22 Jan 2020.

6. James SL, Abate D, Abate KH, Abay SM, Abbafati C, Abbasi N, et al. Global, regional, and national incidence, prevalence, and years lived with disability for 354 diseases and injuries for 195 countries and territories, 1990-2017: a systematic analysis for the global burden of disease study 2017. Lancet. 2018:392(10159):1789-858

7. Lepine JP, Briley M. The increasing burden of depression. Neuropsychiatr Dis Treat. 2011;7(Suppl 1):3-7.

8. Sommer M. Mental health among youth in sweden: Nordic Welfare Centre; 2016. https://nordicwelfare.org/en/publikationer/mental-health-amongyouth-in-sweden/. Accessed 17 Jan 2020.

9. Gunnell D, Kidger J, Elvidge H. Adolescent mental health in crisis. BMJ. 2018; $361: k 2608$

10. Kross E, Verduyn P, Demiralp E, Park J, Lee DS, Lin N, et al. Facebook use predicts declines in subjective well-being in young adults. PLoS One. 2013;8(8):1-6.

11. Sagioglou C, Greitemeyer T. Facebook's emotional consequences: why facebook causes a decrease in mood and why people still use it. Comput Hum Behav. 2014;35:359-63.
12. Simoncic TE, Kuhlman KR, Vargas I, Houchins S, Lopez-Duran NL. Facebook use and depressive symptomatology: investigating the role of neuroticism and extraversion in youth. Comput Hum Behav. 2014;40:1-5.

13. Davila J, Hershenberg R, Feinstein BA, Gorman K, Bhatia V, Starr LR. Frequency and quality of social networking among young adults: associations with depressive symptoms, rumination, and corumination. Psychol Pop Media Cult. 2012;1(2):72-86.

14. Verduyn P, Lee DS, Park J, Shablack H, Orvell A, Bayer J, et al. Passive facebook usage undermines affective well-being: experimental and longitudinal evidence. J Exp Psychol Gen. 2015;144(2):480-8.

15. Tandoc EC, Ferrucci P, Duffy M. Facebook use, envy, and depression among college students: is facebooking depressing? Comput Hum Behav. 2015;43:139-46.

16. Song H, Zmyslinski-Seelig A, Kim J, Drent A, Victor A, Omori K, et al. Does facebook make you lonely?: a meta analysis. Comput Hum Behav. 2014;36:446-52.

17. Sherlock M, Wagstaff DL. Exploring the relationship between frequency of instagram use, exposure to idealized images, and psychological well-being in women. Psychol Pop Media Cult. 2018.

18. Lup K, Trub L, Rosenthal L. Instagram \#instasad?: exploring associations among instagram use, depressive symptoms, negative social comparison, and strangers followed. Cyberpsychol Behav Soc Netw. 2015;18(5):247-52.

19. Rae JR, Lonborg SD. Do motivations for using facebook moderate the association between facebook use and psychological well-being? Front Psychol. 2015;6:771.

20. Lönnqvist J-E, Itkonen JVA. It's all about extraversion: why facebook friend count doesn't count towards well-being. J Res Pers. 2014;53:64-7.

21. Manago AM, Taylor T, Greenfield PM. Me and my 400 friends: the anatomy of college students' facebook networks, their communication patterns, and well-being. Dev Psychol. 2012;48(2):369-80.

22. Appel H, Gerlach AL, Crusius J. The interplay between facebook use, social comparison, envy, and depression. Curr Opin Psychol. 2016;9:44-9.

23. Santini Zl, Koyanagi A, Tyrovolas S, Mason C, Haro JM. The association between social relationships and depression: a systematic review. J Affect Disord. 2015;175:53-65.

24. Zimet GD, Dahlem NW, Zimet SG, Farley GK. The multidimensional scale of perceived social support. J Pers Assess. 1988:52(1):30.

25. Strine TW, Chapman DP, Balluz L, Mokdad AH. Health-related quality of life and health behaviors by social and emotional support. Soc Psychiatry Psychiatr Epidemiol. 2008;43(2):151-9.

26. Duggan M, Ellison NB, Lampe C, Lenhart A, Madden M. Social media update 2014. Pew Res Center. 2015;19.

27. Carlsson F, Merlo J, Lindström M, Östergren P-O, Lithman T. Representativity of a postal public health questionnaire survey in Sweden, with special reference to ethnic differences in participation. Scand J Public Health. 2006; 34(2):132-9.

28. Phillips S. A brief history of facebook: The Guardian; 2007. https://www. theguardian.com/technology/2007/jul/25/media.newmedia. Accessed 15 Apr 2019.

29. Goldberg DP, Blackwell BJ. Psychiatric illness in general practice: A detailed study using a new method of case identification. BMJ. 1970;2(5707):439-43.

30. Baldwin JA. Detection of illness. Br J Psychiatry. 1973;122(569):483.

31. Romppel M, Braehler E, Roth M, Glaesmer H. What is the general health questionnaire-12 assessing?: dimensionality and psychometric properties of the general health questionnaire-12 in a large scale german population sample. Compr Psychiatry. 2013:54(4):406-13.

32. Goldberg DP, Gater R, Sartorius N, Ustun TB, Piccinelli M, Gureje O, et al. The validity of two versions of the ghq in the who study of mental illness in general health care. Psychol Med. 1997;27(1):191-7.

33. Goldberg DP, Oldehinkel T, Ormel J. Why ghq threshold varies from one place to another. Psychol Med. 1998;28(4):915-21.

34. Lundin A, Åhs J, Åsbring N, Kosidou K, Dal H, Tinghög P, et al. Discriminant validity of the 12-item version of the general health questionnaire in a swedish case-control study. Nord J Psychiatry. 2017;71(3):171-9.

35. Aschengrau A, Seage GR. Essentials of epidemiology in public health. Burlington: Jones \& Bartlett Publishers; 2013.

36. Bowers D. Medical statistics from scratch: an introduction for health professionals. Hoboken: Wiley; 2014.

37. Rothman KJ. Modern epidemiology. Boston: Little, Brown and Company; 1986

38. Patel V, Flisher AJ, Hetrick S, McGorry P. Mental health of young people: a global public-health challenge. Lancet. 2007;369(9569):1302-13.

39. Grigoriadis S, Erlick RG. Gender issues in depression. Ann Clin Psychiatry. 2007;19(4):247-55. 
40. Booker CL, Kelly YJ, Sacker A. Gender differences in the associations between age trends of social media interaction and well-being among 1015 year olds in the uk. BMC Public Health. 2018;18(1):321.

41. Sawyer SM, Afifi RA, Bearinger LH, Blakemore S-J, Dick B, Ezeh AC, et al. Adolescence: A foundation for future health. Lancet. 2012;379(9826):1630-40.

42. Eyre O, Thapar A. Common adolescent mental disorders: Transition to adulthood; 2014. p. 1366-8.

43. Frison $\mathrm{E}$, Eggermont $\mathrm{S}$. Exploring the relationships between different types of facebook use, perceived online social support, and adolescents' depressed mood. Soc Sci Comput Rev. 2015;34(2):153-71.

44. Marino C, Gini G, Vieno A, Spada MM. A comprehensive meta-analysis on problematic facebook use. Comput Hum Behav. 2018;83:262-77.

45. Marino C, Gini G, Vieno A, Spada MM. The associations between problematic facebook use, psychological distress and well-being among adolescents and young adults: a systematic review and meta-analysis. J Affect Disord. 2018;226:274-81.

46. Marino C, Finos L, Vieno A, Lenzi M, Spada MM. Objective facebook behaviour: differences between problematic and non-problematic users. Comput Hum Behav. 2017;73:541-6.

47. Kimbrough AM, Guadagno RE, Muscanell NL, Dill J. Gender differences in mediated communication: women connect more than do men. Comput Hum Behav. 2013:29(3):896-900.

48. Krasnova H, Veltri NF, Eling N, Buxmann P. Why men and women continue to use social networking sites: the role of gender differences. J Strateg Inf Syst. 2017;26(4):261-84.

49. Joiner R, Stewart C, Beaney C, Moon A, Maras P, Guiller J, et al. Publically different, privately the same: gender differences and similarities in response to facebook status updates. Comput Hum Behav. 2014;39:165-9.

50. Meyers-Levy J, Loken B. Revisiting gender differences: what we know and what lies ahead. J Consum Psychol. 2015;25(1):129-49.

51. Elisa B, Stefano T. Self-esteem, social comparison, and facebook use. Eur J Psychol. 2018;4:831.

52. Nesi J, Prinstein MJ. Using social media for social comparison and feedbackseeking: gender and popularity moderate associations with depressive symptoms. J Abnorm Child Psychol. 2015;43(8):1427-38.

53. Holland G, Tiggemann M. A systematic review of the impact of the use of social networking sites on body image and disordered eating outcomes. Body Image. 2016;17:100-10.

54. Kendler KS, Myers J, Prescott CA. Sex differences in the relationship between social support and risk for major depression: a longitudinal study of opposite-sex twin pairs. Am J Psychiatr. 2005;162(2):250-6.

55. Almquist YB, Östberg V, Rostila M, Edling C, Rydgren J. Friendship network characteristics and psychological well-being in late adolescence: exploring differences by gender and gender composition. Scand J Public Health. 2013;42(2):146-54.

56. Turel O, Poppa NT, Gil-Or O. Neuroticism magnifies the detrimental association between social media addiction symptoms and wellbeing in women, but not in men: a three-way moderation model. Psychiatry Q. 2018; 89(3):605-19.

57. Swickert $R$, Owens $T$. The interaction between neuroticism and gender influences the perceived availability of social support. Personal Individ Differ. 2010;48(4):385-90.

58. Kim J, Lee J-ER. The facebook paths to happiness: effects of the number of facebook friends and self-presentation on subjective well-being. Cyberpsychol Behav Soc Netw. 2011;14(6):359-64.

59. Lee H, Ahn H, Nguyen TG, Choi S-W, Kim DJ. Comparing the self-report and measured smartphone usage of college students: a pilot study. Psychiatry Investig. 2017;14(2):198-204.

\section{Publisher's Note}

Springer Nature remains neutral with regard to jurisdictional claims in published maps and institutional affiliations.

Ready to submit your research? Choose BMC and benefit from:

- fast, convenient online submission

- thorough peer review by experienced researchers in your field

- rapid publication on acceptance

- support for research data, including large and complex data types

- gold Open Access which fosters wider collaboration and increased citations

- maximum visibility for your research: over $100 \mathrm{M}$ website views per year

At BMC, research is always in progress.

Learn more biomedcentral.com/submissions 